\title{
Techniques of Surgery for Lumbar Spinal Stenosis: A Comparative Study
}

\author{
Abdul Salam Abdul Rahman Hawis, Iacob Gabriel \\ Carol Davila University of Medicine and Pharmacy, Bucharest, Romania \\ Email: hawis1978@gmail.com
}

How to cite this paper: Hawis, A.S.A.R. and Gabriel, I. (2019) Techniques of Surgery for Lumbar Spinal Stenosis: A Comparative Study. Open Journal of Modern Neurosurgery, 9, 78-104. https://doi.org/10.4236/ojmn.2019.91009

Received: May 12, 2018

Accepted: January 27, 2019

Published: January 30, 2019

Copyright $\odot 2019$ by author(s) and Scientific Research Publishing Inc. This work is licensed under the Creative Commons Attribution International License (CC BY 4.0).

http://creativecommons.org/licenses/by/4.0/

\section{cc) (7) Open Access}

\begin{abstract}
Aim: To compare between classic open surgeries and minimally invasive surgeries in Lumbar Spinal Stenosis. Methods: A comparative descriptive study, involved 117 patients suffering from lumbar canal stenosis, aged between 40 - 70 years; admitted to department of Neurosurgery from March 2011 till august 2016 in King Fahad Hospital in Saudi Arabia. Study groups are consisted of group A as patients managed with classical laminectomy, group $\mathrm{B}$ as patients managed with endoscopic spinal procedures and group $\mathrm{C}$ as patients managed with microscopic decompression facilitated by the $\mathrm{Me}-$ trex Tubular System. SPSS was used in data entry and analysis, and ethical considerations taken into consideration and participants filled the required inform consents. Results: Age of particaoncet ranged from 45 - 63 years, Mean $+/-50$. The degenerative canal stenosis with acute disc single level (cauda equina syndrome) was the most common type of lumbar canal stenosis encountered in group A; the unilateral foraminal and lateral recess stenosis without disc prolapse was the most common type of lumbar canal stenosis encountered in group B; while the unilateral foraminal and lateral recess stenosis without disc prolapse was the most common type of lumbar canal stenosis encountered in group C. Classic laminectomy and disectomy used mostly in group A; endoscopic unilateral decompression lamino-foraminotomy without discectomy used mostly in group B and bilateral microscopic laminectomy without discectomy followed by unilateral microscopic laminoforaminotomy without discectomy used mostly in group C. Mean of operation duration was the highest in both gender of group A, followed by group B, then group C. Unintended durotomy was the most common intra operative complications occurred in the whole study especially in group A. Mean of blood lost was the highest in both gender of group A, followed by group B, then group C. Postop complications in the patients of study groups were the highest in group A (33.3\%), followed by group B (8.5\%) and then group C (2\%). Conclusion: Microscopic decompression facilitated by the Metrex Tu-
\end{abstract}


bular System is the most effective technique of Surgery for Lumbar Spinal Stenosis and the least intra-operative and post-operative complications.

\section{Keywords}

Invasive, Microscopic, Techniques, Surgery,

Lumbar Spinal, Stenosis

\section{Introduction}

Lumbar spinal stenosis (LSS) is a common and often disabling, well-recognized spinal disorder that generally occurs in the sixth or seventh decade of life, although it can uncommonly occur in younger individuals. Degenerative LSS, including intervertebral disc bulge, ligamentum flavum hypertrophy/calcification, facet joint hypertrophy, causes neural compression in the vertebral canal, lateral recess, or intervertebral foramen, resulting in pain, impaired function, and decreased quality life [1]-[39].

Lumbar spinal stenosis or "loss of epidural reserve" could affect the central lumbar spinal canal \pm lateral recess \pm the neuro-foramen or any combination of these, causing nervous impingement and vascular structures compression [36] [40]-[75]. Lumbar canal stenosis is the disease of elderly patients which interfere with the quality of the life of those patients which cannot tolerate the pain and their function is impaired.

Recently, there was increasing in the diagnosis of LSS due to the revolution in the radiological machines and increasing our experience in this disease as it is become the most common spinal surgery nowadays. Surgical treatment of LSS is recommended after failure of conservative medical therapy; however, the optimal procedure is still debated [45] [73] [74].

The treatment choice in LSS should consider the followings:

A medical treatment should precede the surgical one.

There is no recommendation referring to the timing of surgery, except motor deficit, cauda equina syndrome with bladder/bowel dysfunction.

It is important to inform the patient about the difference between lumbar pain and the diagnosis of radicular syndrome and that surgery is not effective in lumbar pain.

The number of nerve roots requiring decompression is often smaller than what appears in radiological studies. Therefore, surgical procedures should not be based on X-ray studies alone.

Our surgical strategy according to the therapeutic objectives, constraints and physiological analysis of imbalances was clearly precised in the informed consent, corresponding with patients expectations: never preventive, minimally invasive decompressive technique for the lumbar canal and the roots, to minimize tissue damage, avoiding destabilization, minimizing time of surgery, postoperative morbidity, length of hospital stay and avoiding complications to achieve a 
good quality of life using a minimally invasive techniques for "maximum effect with minimum trauma", thinking to an unique surgical procedure.

\section{Material and Methods}

A descriptive study involved 100 patients suffering from lumbar canal stenosis, aged between 40 - 75 years; admitted to Department of Neurosurgery from March 2011 till august 2016. Ethical considerations taken into consideration and participants filled the required inform consents. The surgical procedures were only applied after obtaining the informed consent of the patient and in total accordance with the rules and regulations set forth by the ethical committee of the personnel management of King Fahd Hospital (Albaha, KSA) and with the relevant EU laws and Directives. Each patient was requested to sign a form after a satisfactory discussion during which he was informed about all aspects of the surgery and of the study.

\subsection{Study Groups Which Were Classified Accordingly}

Group A: Classical laminectomy.

Group B: Endoscopic spinal procedures.

Group C: Microscopic decompression facilitated by the tubular lumbar system.

All patients of this study were enrolled and surveyed 3, 612 and 24 months post operatory, for symptomatic lumbar spine stenosis at one/several levels or lumbar stenosis with aggravating factors. As a precondition for inclusion in the study, (unsuccessful) conservative treatment was first tried to all patients with radiculalgia, for at least 3 months, in an effort to reduce pain, augmenting walking distance, maintaining a better posterior pelvic tilt, improving muscles strength, endurance and flexibility.

\subsection{Eligibility Criteria}

All patients of this study were enrolled and surveyed 3, 612 and 24 months post operatory, for symptomatic lumbar spine stenosis at one/several levels or lumbar stenosis with aggravating factors. As a precondition for inclusion in the study, unsuccessful conservative treatment was first tried to all patients with radiculalgia, for at least 3 months, in an effort to reduce pain, augmenting walking distance, maintaining a better posterior pelvic tilt, improving muscles strength, endurance and flexibility. Co-existing multiple or single level disc prolapse with a multistage lumbar spinal stenosis without scoliosis, degenerative listhesis and posterior arthrosis at one or several levels, scoliosis with a small and a big radius of curvature and facet joint cyst.

The conservative treatment methods that were used based on observation and clinical judgments included: activity restrictions like avoiding hyperextension and side bending, lumbo-sacral orthoses for a limited number of hours per day, to avoid atrophy of paraspinal muscles, physical therapy as active exercises in the form of stretching to increase lumbo-pelvic muscular stabilization, distraction, 
manipulation and neural mobilization, encouraging lumbar flexion and flattening of the lumbar lordotic curve, also exercises performed during lumbar flexion, such as bicycling, In addition to massage, acupuncture, biofeedback, hot or cold packs and ultrasounds, analgesics such as anti-inflammatory medications, vasodilators, anxiolytic and antidepressive medication, and epidural injections with corticoid products made blindly or under fluoroscopic control that used when pain relievers were ineffective and conservative treatment has failed to give adequate results in 3 months, surgical alternative was applied in all patients.

\subsection{Statistical Analysis}

SPSS v. 18 was used in data entry and analysis to evaluate the dependence of the scores on the independent variables I have used the statistical test ANACOVA employing the Fisher test $\mathrm{F}$ which analyzes the covariance of the variable of interest with each of the independent variables. This test informs if the set of independent variables explains the fluctuations of the dependent variable (the scores).

To evaluate which of the independent variables (i.e. age, sex, group, etc.) explains (or causes) the fluctuations (i.e. the improvement of the scores) one has to examine the $\mathrm{F}$ value and the probability that $\mathrm{Pr}>\mathrm{F}$; the value of $\mathrm{F}$ indicates if any of the independent variables (age, sex, etc.) influences significantly the score.

I have also run several prediction models to verify if the scores are significantly influenced by every independent variable but all of them showed to be insignificant, so that in most cases the models accepted only one variable so only working model remained the linear regression.

When examining the evolution of the outcome scores at various moments in time, we must also demonstrate that the scores differ significantly between different moments 0 - 24; if the differences between the values of the scores taken at different moments in time are statistically significant.

To answer to this question while eliminating the problem of the irresolute statistical distribution of the score values (i.e. normal vs. abnormal distributions) I have used both parametric and nonparametric statistical test.

Under the assumption of a normal distribution of the results I have used the parametric test ANOVA which indicates if there are significant differences between score values over time. For the cases when there was a statistically significant difference between score values in time (using the cutting value $\mathrm{Pr}>\mathrm{F}$ under 0.05), I have used the Bonferroni test to discover which scores differed significantly.

The test parameters used for the ANOVA procedure are the following:

\begin{tabular}{cc}
\hline Alpha & 0.05 \\
Error Degrees of Freedom & 580 \\
Error Mean Square & 0.515119 \\
Critical Value of t & 2.81782 \\
Minimum Significant Difference & 0.2644 \\
\hline
\end{tabular}


Under the assumption of a distribution of the results other than normal I have used the following nonparametric tests:

- Median One-Way Analysis with Chi-Square and the Median Scores (Number of Points Above Median) for the Variable for ordering the values in time

- Van der Waerden One-Way Analysis with Chi-Square and Van der Waerden Scores (Normal) for Variable for ordering the values in time

- Savage One-Way Analysis with Chi-Square and Savage Scores (Exponential) for Variable for ordering the values in time

- Kolmogorov-Smirnov Statistics (Asymptotic) and Kolmogorov-Smirnov Testfor the values in time

- Cramer-von Mises Statistics (Asymptotic) and Cramer-von Mises Test for Variable for ordering the values in time

- Kruskal-Wallis test using the Wilcoxon Scores (Rank Sums) for Variables to infer the order of the groups.

In all cases and for all tests, average scores were used for ties. To save space, after running several trial tests under several models, I have chosen from the nonparametric tests tried as mentioned above, to present only the Kruskal-Wallis test using the Wilcoxon Scores (Rank Sums) for Variables to infer the order of the groups. Because for the outcome score "Walking distance" only score values from pre-OP and at M24 could be obtained (2 samples), I have chosen the statistical tests Wilcoxon Two-Sample Test, under two approximations, (Normal Approximation and the $t$ Approximation) both run for both One-Sided and Two-Sided variants for which $\mathrm{Z}$ included a continuity correction of 0.5 .

\section{Results}

\subsection{Characteristics of the Study Groups}

Demographic characteristics of group A, classic open laminectomy.

Group A included 21 patients who underwent classic open laminectomy under several procedure variations.

\subsection{Age Distribution of Laminectomy Patients}

The age distribution per gender within group A was balanced between sexes, with a smooth distribution between the extreme ages. The extreme ages, -both minimal (45 in both sexes) and maximal ages (66 vs. 68) in both sexes were well matched as were the age distributions in both sexes, despite the different number of patients per gender in this group, with slightly older (68 vs. 66) male patient.

The patients in group B had ages between 45 and 63 years, with an average age of a 49.2381 years for females and 49.80769 for males. The median value for the group was 48 for the female patients and 49 for the male patients, just a bit lower than the average age for the group, with a standard deviation of 4.369265 years for the female patients and 3.370688 for the male patients, suggesting a well-balanced study group with a distribution only approximating a normal distribution as shown in Table 1 . The extreme ages, both minimal and maximal 
Table 1. Age distribution of study groups.

\begin{tabular}{cccc}
\hline Parameter & Group A & Group B & Group C \\
\hline Minimal age of the whole group & 45 & 45 & 45 \\
Maximal age of the whole group & 63 & 63 & 62 \\
Mean - average age of patient of the whole group & 52.76 & 49.23 & 49.77 \\
Standard deviation of the mean for the whole group & 7.09 & 4.36 & 4.35 \\
Female minimal age & 45 & 45 & 47 \\
Female maximal age & 66 & 63 & 62 \\
Mean - average age of female patient & 53.62 & 49.23 & 49.84 \\
Standard deviation of the mean & 7.90 & 4.36 & 5.16 \\
Median age of the female & 51.5 & 48 & 49 \\
Males minimal age & 45 & 45 & 45 \\
Males maximal age & 68 & 58 & 58 \\
Mean - average age of male patient & 52.23 & 49.80 & 49.5 \\
Standard deviation of the mean in the males & 6.83 & 3.37 & 3.45 \\
Median age of the males & 51 & 49 & 48.5 \\
\hline
\end{tabular}

ages in both sexes were well matched as were the age distributions in both sexes, despite a slightly older (63 vs. 58) female patient and the different number of patients per gender in this group. The overall mean age in Group B was 49.55319, with a standard deviation of 3.815349 for the entire group B, and a general median of 49.

The patients in group $C$ had ages between 45 and 62 and 58 years respectively in females and in males, with an average age of 49.284 years for females and 49.5 for males. The median value for group C was 47 for the female patients and 48.5 for the male patients, just a bit lower than the average age for the group, with a standard deviation of 5.161395 for the female patients and 3.451528 for the male patients, suggesting a well-balanced study group with a distribution only approximating a normal distribution as shown in Table 1.

The overall mean age in Group C was 49.77083, with a standard deviation of 4.357628 for the entire group $\mathrm{C}$, and a general median of 49 . The age distribution by gender, the so called "age pyramid" of the sample, the study group, is very well-shaped for such a small sample size, with a minimal skew due to the difference of 1 case in the age group 45 - 50 years.

\subsection{Type of Pathologies}

The type of pathology exhibited by the patients included in each of the study groups it was surgically distinct for the 3 study groups as shown in Table 2. In this regard, group A exhibited 8 types of pathologies.

The degenerative canal stenosis with acute disc single level was the most common type of lumbar canal stenosis encountered in group A, with 5 cases 
Table 2. Type of pathologies.

\begin{tabular}{|c|c|c|c|c|c|}
\hline Group A & $n$. & Group B & n. & Group C & n. \\
\hline Central lumbar canal stenosis & 4 & $\begin{array}{l}\text { Unilateral foraminal and lateral recess } \\
\text { stenosis without disc prolapse }\end{array}$ & 20 & $\begin{array}{l}\text { Unilateral foraminal and lateral recess } \\
\text { stenosis without disc prolapse }\end{array}$ & 30 \\
\hline Mixed(lateral and central)LSS & 2 & $\begin{array}{l}\text { Unilateral foraminal and lateral recess } \\
\text { stenosis with posterolateral disc prolapse }\end{array}$ & 10 & $\begin{array}{l}\text { Unilateral foraminal and lateral recess } \\
\text { stenosis with posterolateral disc prolapse }\end{array}$ & 6 \\
\hline $\begin{array}{l}\text { Degenerative LSS with facet } \\
\text { cyst single level }\end{array}$ & 1 & $\begin{array}{l}\text { Bilateral foraminal and lateral recess } \\
\text { stenosis without disc prolapse }\end{array}$ & 13 & $\begin{array}{l}\text { Bilateral foraminal and lateral recess } \\
\text { stenosis without disc prolapse }\end{array}$ & 13 \\
\hline $\begin{array}{l}\text { Degenerative LSS with acute } \\
\text { disc prolapse single level }\end{array}$ & 5 & $\begin{array}{l}\text { Bilateral foraminal and lateral recess } \\
\text { stenosis with disc prolapse }\end{array}$ & 4 & & \\
\hline $\begin{array}{l}\text { Unstable LSS with two levels } \\
\text { disc prolapse }\end{array}$ & 3 & & & & \\
\hline $\begin{array}{l}\text { Unstable LSS with one level } \\
\text { disc prolapse }\end{array}$ & 2 & & & & \\
\hline $\begin{array}{l}\text { Unstable LSS with degenerative } \\
\text { scoliosis small curve from L2 to L5 }\end{array}$ & 3 & & & & \\
\hline $\begin{array}{l}\text { Unstable LSS with degenerative } \\
\text { scoliosis big curve from L2 to L5 }\end{array}$ & 1 & & & & \\
\hline
\end{tabular}

more than the central lumbar canal stenosis, which came in second with 4 cases. The least number of cases were encountered for the degenerative canal stenosis with facet cyst single level and the unstable canal stenosis with degenerative scoliosis from L2 - L5 (large curve) which presented only 1 case each.

The patients from group B exhibited 4 types of pathology, as summarized in Table 2.

The unilateral foraminal and lateral recess stenosis without disc prolapse was the most common type of lumbar canal stenosis encountered in group B, with 7 cases more than the bilateral foraminal and lateral recess stenosis without disc prolapse, which came in second with 13 cases. The least number of cases were encountered for the bilateral foraminal and lateral recess stenosis with disc prolapse which presented only 4 cases.

From this we can conclude that the most common type of lumbar canal stenosis encountered in our study is the peripheral one. The patients from group C exhibited 3 types of pathology. The unilateral foraminal and lateral recess stenosis without disc prolapse was the most common type of lumbar canal stenosis encountered in group C, with 7 cases more than the bilateral foraminal and lateral recess stenosis without disc prolapse, which came in second with 13 cases. The least number of cases were encountered for the bilateral foraminal and lateral recess stenosis with disc prolapse which presented only 4 cases.

\subsection{Type of Procedure Used in the Study}

For the surgical management of the patients in the study group A several types of the classical open surgical procedures were used. In this regard, the patients in the study group A had undergone the most numerous variations of surgical 
procedures, as 9 types of procedures were used in this group for only 21 patients in total, as shown in Table 3.

The most common procedure used in group A is the classic laminectomy and disectomy with 5 patients. It was followed by fusion and correction of deformity after bilateral facectomy and decompression from L2 - L5 with 4 cases treated this way.

Three types were the least common procedures each used for 1 patient; these being:

1) Decompression and facectomy and fusion

2) Weiner technique

3) Hinge osteotomy

For the surgical management of the patients in the study group B several types of the minimally invasive surgical procedures with endoscopic approach were used. In this regard, the patients in the study group B had undergone less numerous variations of surgical procedures than group $A$, as only 4 types of procedures were used in this group for a total of 47 patients in this group, as shown in Table 3.

The most common procedure used in group B is the endoscopic unilateral decompression without discectomy which was performed on 20 of the patients in group B.

It was followed by bilateral endoscopic decompression without discectomy. with 13 cases treated this way, almost the same as the endoscopic unilateral decompression with discectomy which was performed on 10 patients. The least common procedure was the bilateral endoscopic lamino-foraminectomy with discectomy used for 4 patients.

Table 3. Types of procedure used in the study groups.

\begin{tabular}{|c|c|c|c|c|}
\hline Group A & $n$. & Group B & n. & Group C \\
\hline $\begin{array}{l}\text { Bilateral decompression laminectomy, } \\
\text { facetectomy from L } 2 \text { to L5 and correction } \\
\text { of degenerative scoliosis by fusion }\end{array}$ & 4 & $\begin{array}{l}\text { Bilateral endoscopic } \\
\text { lamioforaminectomy } \\
\text { with discectomy }\end{array}$ & 4 & $\begin{array}{l}\text { Unilateral microscopic } \\
\text { lamino-foraminotomy } \\
\text { and discectomy one level }\end{array}$ \\
\hline $\begin{array}{l}\text { Laminectomy and medial facetectomy, } \\
\text { discectomy, cage with TLIF fusion }\end{array}$ & 2 & $\begin{array}{l}\text { Bilateral endoscopic } \\
\text { lamioforaminectomy } \\
\text { without discectomy }\end{array}$ & 13 & $\begin{array}{l}\text { Unilateral microscopic } \\
\text { lamino-foraminotomy } \\
\text { two levels }\end{array}$ \\
\hline $\begin{array}{l}\text { Laminectomy and medial facetectomy, } \\
\text { discectomy with PLI fusion }\end{array}$ & 3 & $\begin{array}{l}\text { Endoscopic unilateral } \\
\text { decompression with discectomy }\end{array}$ & 10 & $\begin{array}{l}\text { Bilateral microscopic } \\
\text { lamino-foraminotomy } \\
\text { without discectomy }\end{array}$ \\
\hline $\begin{array}{l}\text { Classic laminectomy } \\
\text { and discectomy }\end{array}$ & 5 & $\begin{array}{c}\text { Endoscopic unilateral } \\
\text { decompression without discectomy }\end{array}$ & 20 & $\begin{array}{l}\text { Unilateral microscopic laminectomy } \\
\text { with discectomy two levels }\end{array}$ \\
\hline $\begin{array}{l}\text { Decompression laminectomy, } \\
\text { facetectomy and fusion }\end{array}$ & 1 & & & $\begin{array}{l}\text { Unilateral microscopic } \\
\text { lamino-foraminotomy one level }\end{array}$ \\
\hline Laminectomy and artherectmy & 2 & & & Unilateral microscopic laminectomy \\
\hline Weiner technique & 1 & & & \\
\hline Hinge osteotomy & 1 & & & \\
\hline $\begin{array}{l}\text { Classic laminectomy and } \\
\text { bilateral foraminectomy }\end{array}$ & 2 & & & \\
\hline
\end{tabular}


For the surgical management of the patients in the study group $\mathrm{C}$ several types of microscopic decompression surgical procedures were used. In this regard, the patients in the study group $C$ had undergone less numerous variations of surgical procedures than groups $\mathrm{A}$, as 5 types of procedures were used for a total of 49 patients in this group, as shown in Table 3 . The most common procedure used in group C (on 13 patients) is the bilateral microscopic laminectomy without discectomy followed by microscopic lamino-foraminotomy without discectomy which was performed on 11 of the patients out of 49 in group C, almost the same as the unilateral microscopic laminectomy. With 10 cases treated this way. The least common procedure was the unilateral microscopic lamino-foraminotomy with discectomy used for 1 patient.

\subsection{Duration of Surgical Interventions}

For the patients included in the study group A, a total number of 2540 hours of intervention time was spent, split 1370/2140 respectively between females and males. The times for the males had a larger variance and standard deviation than for females as shown in Table 4.

In study group, the total time required for the surgical procedures was higher in male patients than in the female patients (2140/1370), also the maximal absolute values (300 $\mathrm{min}$ in males vs. $240 \mathrm{~min}$ in females) and the average times of surgical procedures $(166.92307 \pm 64.5025342 \mathrm{~min}$ in males vs. $171.25 \pm 56.10895$ min in females) but not the minimal absolute times which had higher values in female patients than in male patients ( $90 \mathrm{~min}$ in males vs. $95 \mathrm{~min}$ in females), as shown in Table 4. The median time required for a surgical intervention in group A was also lower in male patients than in female patients (145 min in males vs. 180 min in females).

For the patients included in the study group B a total number of 2434 hours of intervention time was spent, split 1034/1400 respectively between female patients and male patients

Table 4. Duration of surgical interventions among study groups.

\begin{tabular}{|c|c|c|c|}
\hline Parameter & Group A & Group B & Group C \\
\hline Maximal time duration in the Female/Minute group minimal time & 95 & 40 & 30 \\
\hline Minimal time duration in the Female group time & 240 & 70 & 90 \\
\hline Mean duration in the Female group & 171 & 52.8 & 42.8 \\
\hline Standard deviation of the mean in the Female group & 565 & 9.5 & 12.7 \\
\hline Median duration in the Female group & 180 & 55 & 40 \\
\hline Minimal time duration in the in the Male group & 90 & 40 & 30 \\
\hline Maximal time duration in the in the Male group & 300 & 75 & 60 \\
\hline Mean duration in the Male the group & 166 & 53.8 & 43.7 \\
\hline Standard deviation of the mean in the Male group & 64.5 & 11.5 & 8.6 \\
\hline Median duration in the Male the group & 145 & 55 & 45 \\
\hline
\end{tabular}


In study group, the total time required for the surgical procedures was higher in male patients than in the female patients, also the maximal absolute values (75 min in males vs. $70 \mathrm{~min}$ in females) and the average times which had higher values in male patients than in female patients $(53.84615 \pm 11.51588 \mathrm{~min}$ in males vs. $52.85714 \pm 9.561829 \mathrm{~min}$ in females), as shown in Table 4 . The median time required for a surgical intervention in group B was equal in both sexes (55 $\min )$.

For the patients included in the study group C a total number of 2090 hours of intervention time was spent, split 1040/1050 respectively between female patients and male patients. In study group $\mathrm{C}$, the total time required for the surgical procedures was higher in females than in males, also the maximal absolute values (90 min in males vs. $60 \mathrm{~min}$ in females) but not the average times which had higher values in male patients than in female patients $(43.75 \pm 8.628819 \mathrm{~min}$ in males vs. $42.8 \pm 12.75408 \mathrm{~min}$ in females), as shown in Table 4 . The median time in group $\mathrm{C}$ was also higher in males than in females ( $45 \mathrm{~min}$ in males vs. 40 $\min$ in females).

\subsection{Intraoperative Complications}

In the study group A one type of intra-operative complications occurred, represented by unintended durotomy in 3 cases out of 21 , which makes for $14.3 \%$ of the total number of surgical interventions performed in this study group as shown in Table 5.

The patients in group B exhibited only one case of nerve root injury, making for a percentage of complications of $2.1 \%$ in a total number of 47 cases in group $\mathrm{B}$, as shown in Table 5. From the above table we can conclude that patients who had undergone minimally invasive surgeries like endoscopic and microscopic procedures had the least intraoperative complications. Of the 3 intra operative complications occurred in the whole study, the patients in group $\mathrm{C}$ exhibited only one case of failure to access target, making for a percentage of complications of $2 \%$ in a total number of 49 cases in group C, as shown in Table 5.

\subsection{Intra-Operative Blood Loss}

For the patients included in the study group A a total amount of $3150 \mathrm{~mL}$ of blood was lost during surgical procedures, split 1215/1935 mL respectively between female patients and male patients.

Table 5. Intra operative complications of study groups.

\begin{tabular}{cccc}
\hline Complication type & Group A & Group B & Group C \\
\hline Unintended durotomy & 3 & 0 & 0 \\
Failure to access target & 0 & 0 & 1 \\
Nerve root injury & 0 & 1 & 0 \\
Percentage of complications & $14.3 \%$ & $2.1 \%$ & $2 \%$ \\
\hline
\end{tabular}


In study group $\mathrm{A}$, the total amount blood lost during surgical procedures was higher in male patients than in the female patients, both in the maximal absolute individual values $(240 \mathrm{~mL}$ in males vs. $200 \mathrm{~mL}$ in females) and in the average amounts which had higher values in male patients than in female patients $(148.85 \pm 32.414 \mathrm{~mL}$ in males vs. $141.88 \pm 31.275 \mathrm{~mL}$ in females), as shown in Table 4. The median amount of blood lost during surgical procedures was lower though in male patients than in the female patients in group A $(140 \mathrm{~mL}$ vs. 152.5 $\mathrm{mL}$ ).

The very large value of the standard deviation in the male group was due to the one outlier case which lost $240 \mathrm{~mL}$ of blood during the surgical procedure, apparently making the distribution in this segment of group A non-normal distribution. Besides the statistical argument, such a large amount of blood lost in this type of surgical procedure is totally uncharacteristic for such procedure; therefore exclusion of that case from the sample also makes a clinical sense. The unusually high amount of blood lost during the surgical procedure was correlated with a longer procedure and also with the longer time spent in hospital by that patient.

Eliminating the outlier from the sample and excluding the outlier value of 240 $\mathrm{mL}$ brings the maximal amount of blood loss in the male group to $185 \mathrm{~mL}$, a value still higher than the corrected one in the female group $(180 \mathrm{~mL})$, the mean in the male group to $141 \mathrm{~mL}$, the Standard deviation to 18.106 , and the median in males to $140 \mathrm{~mL}$, brings the statistics closer to the ones for the female segment of group A, as shown in Table 6. Deviation in Group A to 31.225, and the median in Group A to $140 \mathrm{~mL}$ are as shown in Table 4. This makes this group relatively well balanced also with regard to the amount of blood loss during surgical procedures, confirming the validity of the sample group. Eliminating the outliers from the sample and excluding the outlier values of $200 \mathrm{~mL}$ and $240 \mathrm{~mL}$ brings the overall maximal amount of blood loss in Group A to $185 \mathrm{~mL}$, the overall mean amount of blood loss in Group A to $145.588 \mathrm{~mL}$, the Standard.

Table 6. Intra-operative blood loss in surgical interventions of study groups.

\begin{tabular}{|c|c|c|c|}
\hline Parameter & Group A & Group B & Group C \\
\hline Minimal amount of blood loss in the Male group $/ \mathrm{ml}$ & 120 & 30 & 15 \\
\hline Maximal amount of blood loss in the Male group & 240 & 80 & 60 \\
\hline Mean amount of blood loss in the Male group & 148.85 & 50.96 & 32.70 \\
\hline Standard deviation of the mean in the Male group & 32.41 & 17.49 & 9.77 \\
\hline Median amount of blood loss in the Male group & 140 & 52.5 & 30 \\
\hline Minimal amount of blood loss in the Female group & 120 & 30 & 15 \\
\hline Maximal amount of blood loss in the Female group & 200 & 75 & 120 \\
\hline Mean amount of blood loss in the Female group & 151.88 & 51.19 & 30.8 \\
\hline Standard deviation of the mean in the Female group & 31.27 & 16.94 & 20.34 \\
\hline Median amount of blood loss in the Female group & 152.5 & 50 & 25 \\
\hline
\end{tabular}


For the patients included in the study group B a total amount of $2400 \mathrm{~mL}$ of blood was lost during surgical procedures, split 1075/11,325 respectively between female patients and male patients

In study group B, the total amount blood lost during surgical procedures was higher in male patients than in the female patients, also the maximal absolute values ( $80 \mathrm{~mL}$ in males vs. $75 \mathrm{~mL}$ in females) but not in the average amounts which had higher values in female patients than in male patients $(51.19048 \pm$ $16.9488 \mathrm{~mL}$ in females vs. $50.96154 \pm 17.49395 \mathrm{~mL}$ in males), as shown in Table 6. The median amount of blood lost during surgical procedures was higher in males than in females in group B (52.5 vs. 50) as shown in Table 6.

\subsection{Post-Operative Complications}

The patients in Group A exhibited relatively many post-operative complications, of 5 types comprising with a total of 7 cases, this making for a percentage of complications of $33.3 \%$ in a total number of 21 cases in group A, as shown in Table 7.

The patients in Group B exhibited few post-operative complications, comprising 3 types ( 2 cases of persistent radiculopathy, and one case each of wound infection and discitis, representing $8.5 \%$ of complications in a total number of 47 cases in group B, as shown in Table 7.

The patients in Group C exhibited even fewer post-operative complications than the other 2 study groups, comprising 1 type (1 cases of persistent radiculopathy), this making for a percentage of complications of $2 \%$ in a total number of 47 cases in group C, as shown in Table 7.

For the patients included in the study group C a total amount of $1555 \mathrm{~mL}$ of blood was lost during surgical procedures, split 770/785 respectively between female patients and male patients In study group C, the total amount blood lost during surgical procedures was higher in female patients than in the malepatients, also the maximal absolute values $(120 \mathrm{~mL}$ in females vs. $60 \mathrm{~mL}$ in males) but not in the average amounts which had higher values in male patients than

Table 7. Postop complications in the patients of study groups.

\begin{tabular}{cccc}
\hline Type of complication & Group A & Group B & Group C \\
\hline CSF leak & 3 & 0 & 0 \\
Persistent weakness & 1 & 0 & 0 \\
Persistent bladder dysfunction & 1 & 0 & 0 \\
Wound infection & 1 & 1 & 0 \\
Persistent LBP & 1 & 0 & 0 \\
Persistent radiculopathy & 0 & 2 & 1 \\
Discitis & 0 & 1 & 0 \\
Total no. of cases & 21 & 47 & 49 \\
Percentage of complications & $33.3 \%$ & $8.5 \%$ & $2 \%$
\end{tabular}


in female patients $(32.70833 \mathrm{~mL} \pm 9.777877 \mathrm{~mL}$ in males vs. $30.8 \mathrm{~mL} \pm 20.34494$ in females), as shown in Table 7. The median amount of blood lost during surgical procedures was higher in male patients than in the female patients in group C ( $30 \mathrm{~mL}$ vs. $25 \mathrm{~mL})$ The very large value of the standard deviation in the female group was due to the one outlier case which lost $120 \mathrm{~mL}$ of blood during the surgical procedure, apparently making the distribution in this segment of group $\mathrm{C}$ a non-normal distribution. Besides the statistical argument, such a large amount of blood lost in this type of surgical procedure is totally uncharacteristic for such procedure; therefore, exclusion of that case from the sample also makes a clinical sense.

The unusually high amount of blood lost during the surgical procedure was correlated with a longer procedure as the patient was converted to open classic laminectomy because she was marked obese and we fail to access our target and also with the longer time spent in hospital by that patient.

Eliminating the outlier from the sample and excluding the outlier value of 120 $\mathrm{mL}$ brings the maximal amount of blood loss in the female group to $50 \mathrm{~mL}$, a value lower than the one in the male group $(60 \mathrm{~mL})$, the mean in the female group to $27.08333 \mathrm{~mL}$, the Standard deviation to 8.459194 , while the median remains $25 \mathrm{~mL}$, bringing the statistics very close to the ones for the male segment of group $\mathrm{C}$ as shown in Table 7.

This makes this group very well balanced also with regard to the amount of blood loss during surgical procedures, confirming the validity of the sample group.

\subsection{Hospital Time Spent by Patients}

For the patients included in the study group A, the total amount of 158 days was spent in hospital associated with the surgical procedures, split 73/85 between female patients and male patients.

In study group $\mathrm{A}$, although the total time spent in hospital associated with the surgical procedures was longer in male patients than in the female patients, the maximal absolute individual values was not (14 in males vs. 21 days in females) but not in the average amounts which had higher values in female patients than in male patients $(9.125 \pm 6.356942212$ days in females vs. $6.538461538 \pm$ 2.78733399 days in males), as shown in Table 8. Though, the median hospital time spent by Laminectomy patients was equal in male patients and in the female patients in group A (5 days).

The very large value of the standard deviation compared to the value of the mean in the female group was due to the one outlier case which spent 21 days in hospital care but also 2 other patients that spent 14 days each in hospital care, apparently making the distribution in this segment of group A a non-normal distribution. Besides the statistical argument, such a long period of time being totally uncharacteristic for such procedure, therefore exclusion of that case from the sample also makes a clinical sense. Eliminating the outlier from the sample and excluding the outlier value of 21 days brings the overall time spent by the 
Table 8. In-hospital time of study groups per day.

\begin{tabular}{cccc}
\hline Parameter per day & Group A & Group B & Group C \\
\hline Minimal hospital time in the in the male group & 4 & 1 & 1 \\
Maximal hospital time in the in the male group & 14 & 5 & 1 \\
Mean time of hospital time in the male group & 6.53 & 1.28 & 0 \\
Standard deviation of the mean in the male group & 2.78 & 0.95 & 2.54 \\
Median time of hospital time in the male group & 5 & 1 & 1 \\
Minimal hospital time in the Female group & 4 & 1 & 1 \\
Maximal hospital time in the Female group & 21 & 14 & 3 \\
Mean time of hospital time in the Female group & 9.12 & 1.53 & 1.12 \\
$\begin{array}{c}\text { Standard deviation of the mean in the Female group } \\
\text { Median time of hospital time in the Female group }\end{array}$ & 6.35 & 2.54 & $\mathbf{0 . 4 3}$ \\
\hline
\end{tabular}

females in hospital care to 52 days, the mean to 7.428571429, the Standard deviation to 4.503966506 , while the median remains 5 , bringing the statistics closer to the ones for the male segment of group A.

For the patients included in the study group B a total amount of 67 days was spent in hospital associated with the surgical procedures, split 27/40 between female patients and male patients

In study group $B$, the total time spent in hospital associated with the surgical procedures was longer in male patients than in the female patients, also the maximal absolute values (14 in males vs. 5 days in females) and also the average hospital times which had higher values in female patients than in male patients (1.538462 \pm 2.549208 days in males vs. $1.285714 \pm 0.956183$ days in females), as shown in Table 8. Though, the median Hospital time spent by MIP Endoscopy patients was equal in male patients and in the female patients in group B (1 day). The standard deviation much greater than the mean in the male group was due to the one outlier case which spent 14 days in hospital care, apparently making the distribution in this segment of group B a non-normal distribution. Besides the statistical argument, such a long period of time being totally uncharacteristic for such procedure, therefore exclusion of that case from the sample also makes a clinical sense.

Eliminating the outlier from the sample and excluding the outlier value of 14 days brings the overall time spent in hospital care to 26 days, the mean to 1.04 , the standard deviation to 0.2 , while the median remains 1 , bringing the statistics very close to the ones for the female segment of group B, as shown in Table 8.

For the patients included in the study group $\mathrm{C}$ a total amount of 52 days was spent in hospital associated with the surgical procedures, split 28/24 between female patients and male patients.

In study group $\mathrm{C}$, although the total time spent in hospital associated with the surgical procedures was longer in male patients than in the female patients, also the maximal absolute values (14 in males vs. 5 days in females) but not in the 
average amounts which had higher values in female patients than in male patients $(1.538462 \pm 2.549208$ days in males vs. $1.285714 \pm 0.956183$ days in females), as shown in Table 8.

Though, the median hospital time spent by Microscopic decompression patients was equal in male patients and in the female patients in group C (1 day). The very large value of the standard deviation compared to the value of the mean in the male group was due to the one outlier case which spent 3 days in hospital care, apparently making the distribution in this segment of group $\mathrm{C}$ a non-normal distribution. Besides the statistical argument, such a long period of time being totally uncharacteristic for such procedure, therefore exclusion of that case from the sample also makes a clinical sense. Eliminating the outlier from the sample and excluding the outlier value of 3 days brings the overall time spent in hospital care to 25 days, the mean to 1.04167 , the Standard deviation to 0.204124 , while the median remains 1 , bringing the statistics very close to the ones for the female segment of group $\mathrm{C}$ as shown in Table 8 .

\section{Discussions}

Lumbar spinal stenosis is a spinal disorder, congenital or acquired, focal or diffuse (multilevel), defining a osteo-ligamentous narrowing (congenital) or shrink (secondary - acquired) of the lumbar spinal canal, a conflict between the lumbar spinal canal with vertebral body osteophytes, hypertrophy of the ligamentum flavum, zygapophyseal joint, lumbar disc hernia or a combination of these and the content represented by the cauda quina roots, lumbar spinal roots and ganglia, generating a complex set of symptoms of which the hallmark is neurogenic claudication, physical findings and radiological abnormalities [1] [2] [6] [20] [27].

Lumbar stenosis (LSS) could appear also with aggravating factors - presented in chapter 5, which should have special considerations and treatment [2] [6] [9] [20] [21] [27] [31] [36] [42] [43] [44] [46] [47]:

- co-existing multiple disk prolapses or single level disk prolapsed with a multistage lumbar spinal stenosis, without scoliosis

- combined LSS with degenerative listhesis and posterior arthrosis at one or several levels

- combined LSS with scoliosis:

- with a small radius of curvature

- scoliosis and a big radius of curvature installed in adolescence

- a big radius of curvature, with rapid evolution $5-10^{\circ}$ in one year generating both

Radiculalgia and instability

- scoliosis with rotation and rapid evolution to 30 - 500 affecting several levels

- combined stenosis and facet joint cyst

- LSS with severe polineuropaty, with or without uni/bilateral paresis

The pathophysiology of spinal stenosis causing neurologic symptoms is likely from a combination of anatomic compression of nerve roots as well as impaired 
blood flow primarily to the nerve roots [1] [2] [5] [6] [10] [11] [12] [13].

To solve such condition, the surgical treatment is not only a solution for resistant symptoms in patients with LSS, but really makes sense: in cases of consistent clinical and radiological findings after adequate conservative therapeutic measures have failed for a time at least three months span of control, to patients with realistic expectations; certified although by few evidence-based insights into the treatment options [1] [2] [3] [6] [7] [10] [11] [12] [13] [14] [20] [21].

There are several points to consider into the preoperative planning:

Medical status \& physiologic age of the patient, clinical and morphologic aspects, co-morbidities, if LSS is symptomatic.

It's also art of surgery - adequacy for enlarged lumbar spinal canal - it's a balance between doing too much and not doing enough: suppressing the conflict between the lumbar spinal canal with disco-ligamentary structures and the content represented by the dural sac and radicular nerves, decompressing the neural foramina, eliminating pressure on the spinal nerve roots, without generating spinal instability, never prophylactic. It means also a functional surgery - never operate pictures with the aim to alleviate symptoms; surgical treatment should be applied to each patient, with a perfect correspondence between neuro-radiologic and clinical findings, to normalize daily life activities, improving functional capacity, achieving a good quality of life the timing for surgery has not been clearly decided. Data comparing the outcomes of patients who underwent surgery earlier versus later in the disease suggest no difference in outcome is there deformity/instability too?, the suggested decompression technique alone may lead to segmental instability? A fusion technique should be performed to all cases?, see loss of mobility of the operated segment, possible adjacent segment decompensation or unless instability is present pre-op; for older patients ability to fuse may be compromised, also fixation may not be adequate.

It's mandatory to inform patient that LSS surgery has no action on: focal or diffuse low back pain and/or stiffness, "degenerative" illness, no patient will be completely free of complaints, no patient will have a new lumbar spine after the operationit's a difficult surgery, most aged patients, fragile, with chronic illness; thinking to an unique surgical procedure, but there are still $20 \%$ unsatisfactory resultsthe proposed surgical procedure should achieve a good quality of life using a technique for "maximum effect with minimum trauma": continue with current best practice - surgical expertise - relating especially to modern techniques and experience for patient selection \& for surgical skills, inform patients of surgical choices and availability of resources and facilities in institution, using local or regional anesthesia combined with conscious sedation - informed consent, with the aim to minimize tissue disruption, decompress the lumbar channel and the roots, avoid reintervention, never preventive, avoid to destabilize, no stabilization, no instrumentation, minimal blood loss, minimize time of surgery and length of hospital stay, minimize post operative morbidity, avoiding complications, with earlier return to activities and work; easier operative approach in obese patients. 
While this debilitating condition has been treated successfully in the past with open laminectomies, MISS approaches are rapidly becoming the "standard" technique used by spine surgeons. The development of minimally invasive surgical techniques is driven by the quest for better patient outcomes. There is some evidence for the use of minimally invasive surgery for degenerative lumbar spine stenosis (LSS), but there are currently no studies comparing outcomes with matched controls [20] [21] [22] [23] [24] [27] [28] [29] [32] [33] [34] [37] [38] [40] [48] [49] [51]-[59] [62] [63] [64] [65].

The object of this study was to compare outcomes following minimally invasive spinal decompression procedures to a standard "open" laminectomy for LSS.

The first therapeutic approach should always be the conservative treatment and our study included only patients that had undergone conservative treatment, but failed to show adequate response. This is however consistent with other recent randomized controlled studies have shown greater improvements in patients after surgery than after conservative treatment [12] [14]. A recent systematic review comparing surgery to conservative treatment in LSS suggested that for patients with radicular pain caused by LSS, in whom a trial of $3-6$ months of conservative treatment had failed, surgery did not improve walking ability but improved pain, function than continuing conservative treatment [10]. Small improvements are generally reported by patients treated conservatively and serious complications or deterioration are rare with conservative treatment [1]-[12] [14].

A study done by Parikh [48] included among the possible disadvantages of minimally surgery techniques the increased operation time due to the steep learning curve. This disadvantage was minimal in our study as all the surgical procedures were performed by the same highly skilled surgeon, with extensive experience using both minimally invasive and open techniques, thus eliminating the potential bias due to the steep learning curve. Taking into account the relative sample sizes with a slight larger sample size for males than females, the procedure time distribution over gender of laminectomy patients was well balanced in both sexes, the surgical time required for the various versions of laminectomy performed on the patients in with classic laminectomy being uniformly split between sexes for every time interval (30 - 60 minutes and 60 - 120 minutes and $>240$ minutes) per surgical intervention, but with a slight bias towards shorter times, in comparison to MIS approaches. The median time required for a surgical intervention in endoscopy group was equal in both sexes (55 min) and (30 - 60 minutes and 60 - 120 minutes) per surgical intervention with equal frequency in females and a slight bias towards lower times in males MIS microscopy group.

The intra-operative complication rates may be one of the very few possible disadvantages of MIS techniques, due to difficulty manipulating instruments through a small portal, especially in cases requiring contralateral access [25] [27] [42] [44] [60] [61] [65]: symptomatic CSF leaks, wound infections and post 
operative spinal spondylolisthesis. In my experience unintentional durotomies have decreased with the use of a protective sleeve drill bit and preservation of the underlying ligamentum flavum during bony decompression. The use of a retractable, single sided guard on the pneumatic drill bit protects the dura from inadvertent injury on one side while allowing visualization of the drill bit tip from the other slide. The ligamentum flavum is kept intact until the bony decompression with the drill and Kerrison is completed. The senior author recently showed a 4.5 incidence of durotomies in obese patients undergoing minimally invasive procedures for lumbar stenosis comparing to our study [57].

Regarding the intra-operative complications, we conclude that patients who had undergone minimally invasive surgeries have the least intra-operative complication as follows:

1 patient we failed to access the target in group $\mathrm{C}$ due to patient obesity with a percentage of complications $2 \%$.

1 patient with nerve root injury in group B with a total percentage of complication $2.1 \%$.

On the other hand the rate of complications were higher in group $\mathrm{A}$ in the form of 3 patients had unintended durotomy with a total percentage of 14.3\% regarding the post-operative complications it was higher in Group A as follows:

3 patients with persistent CSF leak.

1 patient with persistent limb and bladder weakness (patient with preoperatory cauda equina).

1 patient with wound infection.

1 patient with persistent LBP with a total percentage of complications $33.3 \%$.

In the other hand, the post-operative complications were less in group B as follows:

2 patients with persistent radiculopathy.

1 patient with post-operative discitis with a total percentage of $8.5 \%$.

The least complications were happened in group $\mathrm{C}$ with only 1 patient with persistent radiculopathy and total percentage of complications $2 \%$ as in a series of studies done by Armin [40], Khoo LT [59], Jayarao M [62].

In a study done by Madjetko [44], Sengupta D. K. [46] [47] post-operative, long term spinal instability is a real concern in patients undergoing laminectomy for lumbar canal stenosis, especially if the patients have pre-operative spondylolisthesis. Review of literature shows that patients with pre-operative spondylolisthesis have a higher rate $(40 \%-100 \%)$ of post operative progression of instability on dynamic x-ray at a long term follow-up [44]. Comparatively, in our study, among the patients with unstable canal stenosis that had been operated by decompression, instrumentation and fusion, progression of instability had occurred in 2 patients $=22.2 \%$. In another study [6] it showed no significant difference in complication and re-operation rates between minimal invasive surgery treated and conventionally treated patients. This could be accounted by our study's short duration of follow-up, as reoperation rates increase in the long term when bony regrowth occurs in an inadequate decompression. However, 
our study showed no significant difference in complication and reoperation rates between ULBD (Unilateral Laminectomy Bilateral Decompression) treated and conventionally treated patients.

Other studies have shown that the difficulty manipulating instruments through a small portal MIS has intrinsic potential disadvantage of literally leaving "little room for mistakes", resulting in more postoperative complications including more significant dural sac retraction and a higher possibility of dural tears [23] [24] [28] [29], higher recurrence and reoperation rates due to minimal exposure leading to inadequate decompression [29] [30] [32]-[41]. Despite these previous findings in the literature, our study failed to find these short-comes of the MIS approach. This could be accounted for by our study's short duration of follow-up, as reoperation rates increase in the long term [34] [35] when bony re-growth occurs in an inadequate decompression; additionally, the procedures in this study were performed by a single senior surgeon with extensive experience using both minimally invasive and open techniques, thus reducing the impact of the learning curve for MIS patients.

Our study demonstrates several benefits of MIS microscopic the post operative course. As most patients with LSS are elderly and have numerous preoperative comorbidities, decreasing postoperative hospital stay, time to mobilization, post operative pain and disability can significantly decrease patient morbidity. Longer hospital stays and delayed recovery are associated with more post operative complications, such as deep vein thrombosis, urinary tract infections, cardio-pulmonary problems, pulmonary embolism, ileus and prolonged narcotic use as well as with and increased cost of care [6] [20] [21].

Therefore, in our study, the significantly shorter average time to mobilization (1.6 vs 33.3 hours) and average duration of post operative hospital stay (55.1 vs 100.8 hours) for patients in the MIS group compared with those in the conventionally treated group were advantages. Mean post operative hospital stay is ranging from 42 to 80 hours [23] [24] [40] and from 45 to 172 hours [21] [25] [26] [29] for ULBD treated and conventionally treated patients, respectively. In another study, [23] which conclude the significantly shorter average time of mobilization (15.6 vs 33.3 hours) and average duration of post operative hospital stay 55.1 vs 100.8 hours for patients in the minimally invasive procedures group compared with those in the conventionally treated group more advantageous. By comparison, in our study the duration of hospital stay was higher in group A with mean hospital stay 7.5 days and shorter B with a mean hospital stay 1.4 days and the shortest period was in group $C$ with 1.06 days.

Opioids have unwanted side effects that may require additional medications and unnecessarily prolong hospital stay [20], therefore decreasing opioid requirements avoids these complications and allows for less complicated recovery, increased patient comfort and faster return to normal activities of daily living. In our study, the mean value of total iv morphine equivalent units consumed was significantly smaller in MIS, treated patients (9.3 vs 42.8 morphine equivalent units). While this could be due to the significantly longer mean post operative 
stay in the conventionally treated group, a significantly larger proportion of patients in the MIS group did not use any opioids at all (52\% vs 15\%). This is supported by Khoo and Fessler's 2002 study [59] in which open-surgery patients required almost 3 times the amount of narcotics as patients treated with micro-endoscopic decompression laminotomy (73.7 vs 31.8 morphine equivalent units, respectively) after adjusting for length of stay. While we cannot definitely state that patients treated with MIS consume fewer morphine equivalents units, we can conclude they are more likely to not use any opioids, suggesting that MIS is associated with less post-operative pain and discomfort.

In the literature, the minimally invasive surgery achieved a significantly greater improvement in post operative pain than did the open approach. However, neither approach was superior in improving function or quality of life. Furthermore, neither approach or satisfaction rate, while greater percentage of patients in the minimally invasive approaches $85 \%$ felt they had a good outcome than the open group $62 \%$, the difference was not statistically significant [49].

Our study showed that there was a significant improvement in patient status in the study group that underwent minimally invasive surgery, it was significant improvement in patient function of both endoscopic $97.8 \%$ and microscopic groups $100 \%$ and significant improvement of the patient self assisting score in the endoscopic group $14 \%$ in the last 3 months to 2.5 over 2 years of annual follow-up and in the microscopic group from $12 \%$ to $2.5 \%$ over the same period.

\section{Conclusion}

The initial management of LSS should be non-surgical. Surgical intervention is considered only in patients with intractable back or radicular pain that interferes with the patients' life style or in occurrence of neurological deficit. Pre-operative detailed assessment of age and other investigations including MRI, dynamic $\mathrm{x}$-rays, and EMG should be reviewed carefully to determine preoperative instability or presence of associated neurological deficit and also to define which level we are going to decompress. We established an extrusive relation between the radiological degree of canal stenosis and the severity of symptoms and its association of neurological deficit. It was noticed that the predominance of back pain over the radicular symptoms has carried less favorable outcome. Also, operating patients after full trials of conservative treatment for at least 3 to 6 months carry a better outcome and it enhances the result of surgery with net improvement of $60 \%$ to $30 \%$.

\section{Conflicts of Interest}

The authors declare no conflicts of interest regarding the publication of this paper.

\section{References}

[1] Wong, A.P., Smith, Z.A., Lall, R.R., Bresnahan, L.E. and Fessler, R.G. (2012) The 
Microendoscopic Decompression of Lumbar Stenosis: A Review of the Current Literature and Clinical Results. Minimally Invasive Surgery.

[2] Armin, S.S., Holly, L.T. and Khoo, L.T. (2008) Minimally Invasive Decompression for Lumbar Stenosis and Disc Herniation. Neurosurgical Focus, 25, E11. https://doi.org/10.3171/FOC/2008/25/8/E11

[3] Atlas, S.J., Deyo, R.A., Keller, R.B., Chapin, A.M., Patrick, D.L., Long, J.M., et al. (1996) The Maine Lumbar Spine Study Part II 1-Year Outcomes of Surgical and Non-Surgical Management Lumbar Spinal Stenosis. Spine, 21, 1787-1795. https://doi.org/10.1097/00007632-199608010-00012

[4] Martin, C.R., Gruszczynski, A.T., Braunsfurth, H.A., Fallatah, S.M., O’Neil, J. and Wai, E.K. (2007) The Surgical Management of Degenerative Lumbar Spondylolisthesis: A Systematic Review. Spine, 32, 1791-1798. https://doi.org/10.1097/BRS.0b013e3180bc219e

[5] Costa, F., Sassi, M., Cardia, A., Ortolina, A., De Santis, A., Luccarrel, G., et al. (2007) Degenerative Lumbar Spinal Stenosis: Analysis of Results in a Series of 374 Patients Treated with Unilateral Laminotomy for Bilateral Microdecomposition. Journal of Neurosurgery. Spine, 7, 579-586. https://doi.org/10.3171/SPI-07/12/579

[6] Sengupta, D.K. and Herkowitz, H.N. (2005) Degenerative Spondylolithesis: Review of Current Trends and Controversies. Spine, 30, s71-s81. https://doi.org/10.1097/01.brs.0000155579.88537.8e

[7] Sengupta, D.K. (2006) Point of View: Dynamic Stabilization, in Addition to Decompression for Lumbar Spinal Stenosis with Degenerative Spondylolisthesis. Spine, 31, 450. https://doi.org/10.1097/01.brs.0000200051.24623.33

[8] Bassewitz, H. and Herkowitz, H. (2001) Lumbar Stenosis with Spondylolisthesis: Current Concepts of Surgical Treatment. Clinical Orthopedics and Related Research, No. 384, 54-60.

[9] Ikuta, K., Arima, J., Tanaka, T., Oga, M., Nakano, S., Sasaki, K., et al. (2005) Short-Term Results of Microendoscopic Posterior Decompression for Lumbar Spinal Stenosis. Technical Note. Journal of Neurosurgery. Spine, 2, 624-633. https://doi.org/10.3171/spi.2005.2.5.0624

[10] O’Toole, J.E., Eichholz, K.M. and Fessler, R.G. (2009) Surgical Site Infection Rates after Minimally Invasive Spinal Surgery: Clinical Article. Journal of Neurosurgery. Spine, 11, 471-476. https://doi.org/10.3171/2009.5.SPINE08633

[11] Shin, J.J., Kuh, S.U. and Cho, Y.E. (2006) Surgical Management of Spontaneous Spinal Epidural Hematoma. European Spine Journal, 15, 998-1004. https://doi.org/10.1007/s00586-005-0965-8

[12] Jayarao, M. and Chin, L.S. (2010) Results after Lumbar Decompression with and without Discectomy: Comparison of the Transspinous and Conventional Approaches. Neurosurgery, 66, 152-160.

[13] Khoo, L.T. and Fessler, R.G. (2002) Microendoscopic Decompressive Laminotomy for the Treatment of Lumbar Stenosis. Neurosurgery, 51, S146-S154.

[14] de Graaf, I., Prak, A., Bierma-Zeinstra, S., Thomas, S., Peul, W. and Koes, B. (2006) Diagnosis of Lumbar Spinal Stenosis: A Systematic Review of the Accuracy of Diagnostic Tests. Spine, 31, 1168-1176. https://doi.org/10.1097/01.brs.0000216463.32136.7b

[15] Likert, R. (1932) A Technique for the Measurement of Attitudes. Archives of Psychology, 140, 1-55.

[16] Malmivaara, A., Slatis, P., Heliovaara, M., Sainio, P., Kinnunen, H., Kankare, J., et 
al. (2007) Surgical or Non-Operative Treatment for Lumbar Spinal Stenosis. A Randomized Controlled Trial. Spine, 32, 1-8. https://doi.org/10.1097/01.brs.0000251014.81875.6d

[17] Mariconda, M., Zanforlino, G., Celestino, G.A., Brancaleone, S., Fava, R. and Milano, C. (2000) Factors Influencing the Outcome of Degenerative Lumbar Spinal Stenosis. Journal of Spinal Disorders, 13, 131-137. https://doi.org/10.1097/00002517-200004000-00007

[18] Mariconda, M., Fava, R. and Gatto, A., Longo, C. and Milano, C. (2002) Unilateral Laminectomy for Bilateral Decompression of Lumbar Spinal Stenosis: A Prospective Comparative Study with Conservatively Treated Patients. Journal of Spinal Disorders \& Techniques, 15, 39-46. https://doi.org/10.1097/00024720-200202000-00006

[19] Oertel, M.F., Ryang, Y.M. and Korinth, M.C., Gilsbach, J.M. and Rohde, V. (2006) Long-Term Results of Microsurgical Treatment of Lumbar Spinal Stenosis by Laminotomy for Bilateral Decompression. Neurosurgery, 59, 1264-1270. https://doi.org/10.1227/01.NEU.0000245616.32226.58

[20] Shin, P., Wong, A.P., Smith, T.R., Lee, A.I. and Fessler, R.G. (2011) Complications of Open Compared to Minimally Invasive Lumbar Spine Decompression. Journal of Clinical Neuroscience, 18, 1360-1364. https://doi.org/10.1016/j.jocn.2011.02.022

[21] Parikh, K., Tomasino, A., Knopman, J., Boockvar, J. and Hartl, R. (2008) Operative Results and Learning Curve: Microscope-Assisted Tubular Microsurgery for 1 and 2 Level Discectomies and Laminectomies. Neurosurgical Focus, 25, E14. https://doi.org/10.3171/FOC/2008/25/8/E14

[22] Jasper, R., Sivabalan, P. and Rao, P.J. (2004) Outcomes after Decompressive Laminectomy for Lumbar Spinal Stenosis: Comparison between Minimally Invasive Unilateral Laminectomy for Bilateral Decompression and Open Laminectomy: Clinical Article. Journal of Neurosurgery, 21, 179-186.

[23] Madjetko, S.M., Connolly, P.J. and Shott, S. (1994) Degenerative Lumbar Spondylotisthesis: A Meta-Analysis of Literatue 1970-1993. Spine, 20, 2256S-2265S. https://doi.org/10.1097/00007632-199410151-00002

[24] Surin, V., Hedelin, E. and Smith, L. (1982) Degenerative Lumbar Spinal Stenosis. Results of Operative Treatment. Acta Orthopedica Scandinavica, 53, 79-85. https://doi.org/10.3109/17453678208992183

[25] Weinstein, J.N., Lurie, J.D., Tosteson, T.D., Hanscom, B., Tosteson, A.N.A., Blood E.A., et al. (2007) Surgical versus Non-Surgical Treatment for Lumbar Degenerative Spondylolisthesis. New England Journal of Medicine, 356, 2257-2270. https://doi.org/10.1056/NEJMoa070302

[26] Weinsterin, J.N., Tosteson, T.D., Lurie, J.D., Teteson, A.N.A., Blood, E., Hanscome, B., et al. (2008) Surgical versus Non-Surgical Theraphy for Lumbar Spinal Stenosis. New England Journal of Medicine, 358, 794-810. https://doi.org/10.1056/NEJMoa0707136

[27] Smith, Z.A. (2012) Obesity and Patient Outcomes Following Lumbar Microendoscopic Decompression of Stenosis-Outcomes and Complications in 111 Conservatively Treated Patients. Northwestern University, Chicago, 19.

[28] Atlas S.J., Keller, R.B., Wu, Y.A., Deyo, R.A. and Singer, D.E. (2005) Long-Term Outcomes of Surgical and Non Surgical Management of Lumbar Spinal Stenosis: 8 to 10 Year Results from Maine Lumbar Spine Study. Spine, 30, 936-943. https://doi.org/10.1097/01.brs.0000158953.57966.c0

[29] Johnsson, K.E. (1995) Lumbar Spinal Stenosis: A Retrospective Study of 163 Cases in Southern Sweden. Acta Orthopedica Scandinavica, 66, 403-405. 
https://doi.org/10.3109/17453679508995574

[30] Mazanec, D.J., Podichetty, V.K. and Hsia, A. (2002) Lumbar Canal Stenosis: Start with Nonsurgical Therapy. Cleveland Clinic Journal of Medicine, 69, 909-917. https://doi.org/10.3949/ccjm.69.11.909

[31] Fritz, J.M., Delitto, A., William, P.T., Welch, C. and Erhard, R.E. (1998) Lumbar Spinal Stenosis: A Review of Current Concepts in Evaluation, Management and Outcome Measurements. Archives of Physical Medicine and Rehabilitation, 79, 700-708. https://doi.org/10.1016/S0003-9993(98)90048-X

[32] Kovacs, F.M., Urrútia, G. and Alarcón, J.D. (2011) Surgery versus Conservative Treatment for Symptomatic Lumbar Spinal Stenosis: A Systematic Review of Randomized Controlled Trials. Spine, 36, E1335-E1351. https://doi.org/10.1097/BRS.0b013e31820c97b1

[33] Herno, A., Airaksinen, O., Saari, T. and Luukkonen, M. (1996) Lumbar Spinal Stenosis: A Matched-Pair Study of Operated and Nonoperated Patients. British Journal of Neurosurgery, 10, 461-465. https://doi.org/10.1080/02688699647087

[34] Agency for Healthcare Research and Quality (2001) Treatment of Degenerative Lumbarspinal Stenosis: Summary. Evidence Report/Technology Assessment Number 32, Rockville. http://www.ahrq.gov/clinic/epcsums/stenosum.htm

[35] Iacob, G. and Craciun, M. (2011) Personal Experience in Lumbar Spinal Stenosis (LSS). Romanian Neurosurgery, 18, 400-411.

[36] Iacob, G. (2011) Neurochirurgia in Managementul Coloanei Dureroase, Congresul Asociatiei Romanepentru Studiul Durerii. Managementul durerii acute pentrumediciidinambulator, Howard-Johnson Grand Plaza, Bucuresti, 14-15.

[37] Iqbal, J. (2008) Surgery for Lumbar Canal Stenosis: Micro or Macro? Dubai Spinal Course.

[38] Jakola, A., et al. (2010) Clinical Outcomes and Safety Assessment in Elderly Patients Undergoing Decompressive Laminectomy for Lumbar Spinal Stenosis: A Prospective Study. BMC Surgery, 10, 34. https://doi.org/10.1186/1471-2482-10-34

[39] Rosen, D.S., et al. (2007) Minimally Invasive Lumbar Spinal Decompression in the Elderly: Outcomes of 50 Patients Aged 75 Years and Older. Neurosurgery, 60, 503-510. https://doi.org/10.1227/01.NEU.0000255332.87909.58

[40] Zairi, F., Arikat, A., Allaoui, M. and Assaker, R. (2013) Transforaminal Lumbar Interbody Fusion: Comparison between Open and Mini-Open Approaches with Two Years Follow-Up. Journal of Neurological Surgery Part A: Central European Neurosurgery, 74, 131-135.

[41] Wiltse, L.L., Kirkaldy-Willis, W.H. and McIvor, G.W. (1976) The Treatment of Spinal Stenosis. Clinical Orthopaedics and Related Research, 115, 83-91. https://doi.org/10.1097/00003086-197603000-00014

[42] Rahman, H.A. and Iacob, G. (2015) Treatment of Lumbar Spinal Stenosis (LSS) and Outcome. Romanian Neurosurgery, 29, 203-232.

https://doi.org/10.1515/romneu-2015-0030

[43] Ruetten, S., Komp, M., Merk, H. and Godolias, G. (2008) Full-Endoscopic Interlaminar and Transforaminal Lumbar Discectomy versus Conventional Microsurgical Technique: A Prospective, Randomized, Controlled Study. Spine, 33, 931-939. https://doi.org/10.1097/BRS.0b013e31816c8af7

[44] Guiot, B.H., Khoo, L.T. and Fessler, R.G. (2002) A Minimally Invasive Technique for Decompression of the Lumbar Spine. Spine, 27, 432-438.

https://doi.org/10.1097/00007632-200202150-00021 
[45] Papavero, L., et al. (2009) Lumbar Spinal Stenosis: Prognostic Factors for Bilateral Microsurgical Decompression Using a Unilateral Approach. Neurosurgery, 65, ons182-ons187. https://doi.org/10.3171/spi.2005.3.2.0129

[46] Thomé, C., Zevgaridis, D., Leheta, O., Bäzner, H., Pöckler-Schöniger, C., Wöhrle, J. and Schmiedek, P. (2005) Outcome after Less-Invasive Decompression of Lumbar Spinal Stenosis: A Randomized Comparison of Unilateral Laminotomy, Bilateral Laminotomy, and Laminectomy. Journal of Neurosurgery: Spine, 3, 129-141. https://doi.org/10.3171/spi.2005.3.2.0129

[47] Colak, A., et al. (2008) A Less Invasive Surgical Approach in the Lumbar Lateral Recess Stenosis: Direct Approach to the Medial Wall of the Pedicle. European Spine Journal, 17, 1745-1751. https://doi.org/10.1007/s00586-008-0801-Z

[48] Tuite, G.F., et al. (1994) Outcome after Laminectomy for Lumbar Spinal Stenosis. Part II: Radiographic Changes and Clinical Correlations. Journal of Neurosurgery, 81, 707-715. https://doi.org/10.3171/jns.1994.81.5.0707

[49] Tuite, G.F., et al. (2007) Diagnosis and Treatment of Surgery for Lumbar Spinal Stenosis. North American Spine Society (NASS), Burr Ridge, 262.

[50] Iacob, G., Craciun, M. and Hawis, A.A. (2015) General Considerations in Lumbar Spinal Stenosis (LSS). Romanian Neurosurgery, 22, 77-84.

[51] Iacob, G., Craciun, M. and Hawis, A.A. (2015) Treatment of Lumbar Spinal Stenosis (LSS) and Outcome. Romanian Neurosurgery, 29, 200-229.

[52] Djurasovic, M., Glassman, S.D., Carreon, L.Y. and Dimar, J.R. (2010) Contemporary Management of Symptomatic Lumbar Spinal Stenosis. Orthopedic Clinics of North America, 41, 183-191. https://doi.org/10.1016/j.ocl.2009.12.003

[53] Amundsen, T., et al. (2000) Lumbar Spinal Stenosis: Conservative or Surgical Management? A Prospective 10-Year Study. Spine, 25, 1424-1436. https://doi.org/10.1097/00007632-200006010-00016

[54] Young, S., Veerapen, R. and O’laoire, S.A. (1988) Relief of Lumbar Canal Stenosis Using Multilevel Subarticular Fenestrations as an Alternative to Wide Laminectomy: Preliminary Report. Neurosurgery, 23, 628-633. https://doi.org/10.1227/00006123-198811000-00014

[55] Atlas, S.J., Keller, R.B., Robson, D., Deyo, R.A. and Singer, D.E. (2000) Surgical and Nonsurgical Management of Lumbar Spinal Stenosis: Four-Year Outcomes from the Maine Lumbar Spine Study. Spine, 25, 556-562. https://doi.org/10.1097/00007632-200003010-00005

[56] Verbeek, J., Sengers, M.-J., Riemens, L. and Haafkens, J. (2004) Patient Expectation of Treatment for Back Pain. A Systematic Review of Qualitative and Quantitative Studies. Spine, 29, 2309-2318. https://doi.org/10.1097/01.brs.0000142007.38256.7f

[57] Cooper, G., Lutz, G.E., et al. (2004) Effectiveness of Transforaminal Epidural Steroid Injections in Patients with Degenerative Lumbar Scoliotic Stenosis and Radiculopathy. Pain Physician, 7, 311-317.

[58] Fukusaki, M., Kobayashi, I., Hara, T. and Hara, T. (1998) Symptoms of Spinal Stenosis Do Not Improve after Epidural Steroid Injection. Clinical Journal of Pain, 14, 148-151. https://doi.org/10.1097/00002508-199806000-00010

[59] Armon, C., Argoff, C.E., Samuels, J. and Backonja, M.-M. (2007) Assessment: Use of Epidural Steroid Injections to Treat Radicular Lumbo-Sacral Pain: Report of the Therapeutics and Technology Assessment Subcommittee of the American Academy of Neurology. Neurology, 68, 723-729.

https://doi.org/10.1212/01.wnl.0000256734.34238.e7 
[60] Simotas, C.A., Dorey, F.J., Hansraj, K.K. and Cammisa, F. (2000) Nonoperative Treatment for Lumbar Spinal Stenosis. Clinical and Outcome Results and a 3-Year Survivorship Analysis. Spine, 25, 197-203. https://doi.org/10.1097/00007632-200001150-00009

[61] Costandi, S., Chopko, B., Mekhail, M., Dews, T. and Mekhail, N. (2015) Lumbar Spinal Stenosis: Therapeutic Options Review. Pain Practice, 15, 68-81. https://doi.org/10.1111/papr.12188

[62] Porter, R.W. and Miller, C.G. (1998) Neurogenic Claudication and Root Claudication Treated with Calcitonin. A Double-Blind Trial. Spine, 13, 1061-1064. https://doi.org/10.1097/00007632-198809000-00015

[63] Podichetty, V.K., Segal, A.M., Lieber, M. and Mazanec, D.J. (2004) Effectiveness of Salmon Calcitonin Nasal Spray in the Treatment of Lumbar Canal Stenosis: A Double-Blind, Randomized, Placebo-Controlled, Parallel Group Trial. Spine, 29, 2343-2349. https://doi.org/10.1097/01.brs.0000143807.78082.7f

[64] Yoshihara, H. and Prostaglandin, E. (2015) Treatment for Lumbar Spinal Canal Stenosis. Review of the Literature, Pain Practice.

[65] Toyonne, T., Tadashi, T., Daisuke, K., Ryutaku, K. and Makoto, O. (2005) Patients' Expectations in Lumbar Spine Surgery. Spine, 30, 2689-2694.

https://doi.org/10.1097/01.brs.0000187876.14304.15

[66] Iwatsuki, K., Yoshimine, T. and Aoki, M. (2007) Bilateral Interlaminar Fenestration and Unroofing for the Decompression of Nerve Roots by Using a Unilateral Approach in Lumbar Canal Stenosis. Surgical Neurology, 68, 487-492. https://doi.org/10.1016/j.surneu.2006.12.044

[67] Podichetty, V.K., Spears, J., Isaacs, R.E., Booher, J. and Biscup, R.S. (2006) Complications Associated with Minimally Invasive Decompression for Lumbar Spinal Stenosis. Clinical Spine Surgery, 19, 161-166.

[68] Rodriguez-Vela, J., Lobo-Escolar, A., Joven-Aliaga, E., Herrera, A., Vicente, J., Sunen, E., Loste, A. and Tabuenca, A. (2009) Perioperative and Short-Term Advantages of Mini-Open Approach for Lumbar Spinal Fusion. European Spine Journal, 18, 1194-1201. https://doi.org/10.1007/s00586-009-1010-0

[69] Endoscopy Guidelines from ISMISS (2008).

[70] Yoshida, M., Ueyoshi, A., Maio, K., Kawai, M. and Nakagawa, Y. (2005) Surgical Procedures and Clinical Results of Endoscopic Decompression for Lumbar Canal Stenosis. In: Dezawa, A., Chen, P.Q. and Chung, J.Y., Eds., State of the Art for Minimally Invasive Spine Surgery, Springer-Verlag, Tokyo, 15-24. https://doi.org/10.1007/4-431-26666-6_3

[71] Foley, K.T. and Smith, M.M. (1997) Microendoscopic Discectomy. Techniques in Neurosurgery, 3, 301-307.

[72] Ji, Y.C., Kim, Y.B., Hwang, S.N., Park, S.W., Kown, J.T. and Min, B.K. (2005) Efficacy of Unilateral Laminectomy for Bilateral Decompression in Elderly Lumbar Spinal Stenosis. Journal of Korean Neurosurgical Society, 37, 410-415.

[73] Turner, J.A., Ersek, M., Herron, L. and Deyo, R. (1992) Surgery for Lumbar Spinal Stenosis, Attempt Meta-Analysis of the Literature. Spine, 17, 1-8. https://doi.org/10.1097/00007632-199201000-00001

[74] Yoshida, M., Ueyoshi, A., Maio, K., Kawai, M. and Nakagawa, Y. (2005) Surgical Procedures and Clinical Results of Endoscopic Decompression for Lumbar Canal Stenosis. In: State of the Art for Minimally Invasive Spine Surgery, Springer, Tokyo, 15-24. https://doi.org/10.1007/4-431-26666-6_3 
[75] Harkema, S., Gerasimenko, Y., Hodes, J., Burdick, J., Angeli, C., Chen, Y., Ferreira, C., Willhite, A., Rejc, E., Grossman, R.G. and Edgerton, V.R. (2011) Effect of Epidural Stimulation of the Lumbosacral Spinal Cord on Voluntary Movement, Standing, and Assisted Stepping after Motor Complete Paraplegia: A Case Study. The Lancet, 377, 1938-1947. https://doi.org/10.1016/S0140-6736(11)60547-3 


\section{Abbreviations}

CSS: Central Spinal Stenosis

CT: Computed Tomography

D: Decompression

DF: Decompression and Fusion

DOS: Duration of Symptoms

DS: Degenerative Spondylolisthesis

FS: Foraminal Stenosis

LRS: Lateral Recess Stenosis

LSS: Lumbar Spinal Stenosis

ODI: Oswestry disability index

PLIF: Postero-Lateral Interbody Fusion

RCT: Randomized controlled trial

SD: Standard Deviation

SF-36: Medical outcomes study short form survey, 36 items SPORT: Spine Outcomes Research Trial

VAS: Visual Analog Scale

GE: General Electric

SRFS: Self Reported Functional Status

SSWBS: Symptoms Specific Well-Being Score

GWBS: General Well-Being Score

ANACOVA: Data Analysis

FT: Fisher Test

ANOVA: Analysis of Data

MIS: Minimal Invasive Surgery

CSF: Cerebrospinal Fluid

CS: Canal Stenosis

ULBD: Unilateral Laminectomy Bilateral Decompression

EMG: Electromyogram

DVT: Deep Venus Thrombosis

MIP: Minimal Invasive Procedure

TLIF: Transforaminal Lumbar Interbody Fusion 